\title{
A multivariate study of the rGO/g-C3N4 composite for the photocatalytic degradation of bisphenol A: Characterization, degradation kinetics, products identification, and ecotoxicity
}

Chubraider Xavier ( $\nabla$ chubraiderxavier@usp.br)

Universidade de São Paulo https://orcid.org/0000-0001-5858-1539

\section{Bianca Rebelo Lopes}

UFSCar CCET: Universidade Federal de Sao Carlos Centro de Ciencias Exatas e de Tecnologia

\section{Caue Ribeiro}

Embrapa: Empresa Brasileira de Pesquisa Agropecuaria

\section{Eduardo Bessa Azevedo}

University of Sao Paulo Institute of Chemistry of Sao Carlos: Universidade de Sao Paulo Instituto de Quimica de Sao Carlos

\section{Research Article}

Keywords: rGO, g-C3N4, bisphenol A, heterogeneous photocatalysis, experimental design

Posted Date: June 18th, 2021

DOI: https://doi.org/10.21203/rs.3.rs-415112/v1

License: (c) This work is licensed under a Creative Commons Attribution 4.0 International License. Read Full License 


\section{Abstract}

Bisphenol A (BPA), a common polymer plasticizer, is a contaminant of emerging concern with endocrine disrupting activity. Among existing abatement methods, photodegradation demands easily fabricated, inexpensive, high photoactive catalysts, leading to non-toxic byproducts after degradation. It is proposed an optimized (surface response methodology) catalyst for those goals: graphitic carbon nitride impregnated with reduced graphene oxide. The method was based on the sonication of preformed particles followed by reduction with hydrazine in reflux, a methodology that allows for better reproducibility and larger specific surface areas. The catalyst removed $90 \%$ of BPA $\left(100 \mathrm{~mL}, 100 \mu \mathrm{L} \mathrm{L}^{-1}\right)$ in 90 min under UV irradiation (365 nm, $26 \mathrm{~W}$ ) compared to $50 \%$ with pure $\mathrm{g}-\mathrm{C}_{3} \mathrm{~N}_{4}$ (pseudo-first-order kinetics). Tests with radicals scavengers revealed that superoxide radical was the main oxidation agent in the system. By mass spectrometry, two major degradation products were identified, which were less ecotoxic than BPA towards a series of organisms, according to in silico estimations performed with the ECOSAR 2.0 software.

\section{Introduction}

The use of water resources is a critical topic of discussion and technology development. $61 \%$ of the world population has no access to safely managed drinking water services, and approximately $48 \%$ of the population drinks water with no kind of treatment at all. Therefore, the importance of developing water treatment technologies is undeniable (UNESCO,2019).

The traditional drinking water treatment is mainly based on the physical-chemical processes of floc-coagulation followed by decantation and disinfection. Those processes are not designed to remove pollutants that occur at concentrations ranging from $\mathrm{ng} \mathrm{L}^{-1}$ to $\mu \mathrm{g}^{-1}$, which are not currently analyzed by the environmental agencies. Although those pollutants, known as Contaminant of Emerging Concern (CEC), may not cause acute effects on a variety of organisms, their chronic effects are reported in the literature (Ankley et al., 2008).

An example of CEC is bisphenol A (BPA), a plasticizer agent largely used in several industries, which presents endocrine disrupting activity. BPA-laden water consumption is associated with human health problems like infertility, obesity, cancer, and attention deficit hyperactivity disorder - ADHD (Ziv-Gal, Flaws, 2016; Wassenaar, et al., 2017; Rochester et al., 2018). Moreover, BPA is recalcitrant to chlorination and ozonation (Reddy et al., 2018).

Among the available methods for BPA abatement, heterogeneous photocatalysis is an efficient complementary technology to the traditional drinking water ones. That method is based on the light absorption capability of semiconductors, forming electron-hole pairs that perform redox reactions. The process efficiency is mainly affected by the charge carriers recombination time.

Titanium dioxide $\left(\mathrm{TiO}_{2}\right)$ is the most common semiconductor for that purpose due to relatively low recombination rates, but it only can be activated by ultraviolet light (UVA), rendering it less efficient for solar-based treatments (Moma, Baloyi, 2019). Several materials ( $\left.\mathrm{ZnO}, \mathrm{Mn}_{x} \mathrm{O}_{y}, \mathrm{CdS}\right)$, with smaller bandgaps, have been reported as replacements for $\mathrm{TiO}_{2}$, as they may be more easily activated by solar light. However, metal-based semiconductors may ultimately contaminate the treated water with metallic ions (secondary pollution), motivating research about metal-free semiconductors (Cao et al., 2013; Obregón, Colón, 2014; Adhikari et al, 2015; Ai et al., 2015).

Graphitic carbon nitride $\left(\mathrm{g}-\mathrm{C}_{3} \mathrm{~N}_{4}\right)$ is an adequate choice due its simple preparation from inexpensive precursors (melamine or urea) and high synthesis throughput. Although it is activated by visible light, its charge recombination rate is high ( $\mathrm{Ai}$ et al., 2015; Chen et al., 2016). To increase its charge separation, $\mathrm{g}-\mathrm{C}_{3} \mathrm{~N}_{4}$ can be associated with reduced graphene oxide ( $\mathrm{rGO}$ ), producing a metal-free composite, where rGO concentrates electrons, while $\mathrm{g}-\mathrm{C}_{3} \mathrm{~N}_{4}$ is expected to concentrate holes [Hao et al., 2017; Gu et al., 2018; Qian et al. 2018, Wan et al., 2018). 
rGO is produced by the reduction of graphene oxide (GO), from graphite oxide (GrO) exfoliation - an inexpensive precursor as well. It is largely associated with a variety of semiconductors, enhancing their photocatalytic activity by acting as an electron-acceptor (Mural et al., 2015; Nikokavoura, Trapalis, 2017; 2018; Meng, Zhang, 2018).

$\mathrm{rGO} / \mathrm{g}-\mathrm{C}_{3} \mathrm{~N}_{4}$ composites can be produced by thermal or sonochemical approaches (Wan et al., 2018, Aleksandrzak, et al., 2017). While the thermal path usually leads to poor distribution of $r G O$ into de $g-C_{3} N_{4}$ matrix, the sonochemical approach may generate materials with larger specific surface areas, materials with improved reduction, besides less energy consumption in comparison to the other path. Moreover, the experimental conditions are easily controlled and reproduced (Duan et al., 2015).

Although $\mathrm{rGO} / \mathrm{g}-\mathrm{C}_{3} \mathrm{~N}_{4}$ preparation conditions have been previously described, the photocatalytic efficiencies of the prepared composites were very different, even in similar works that typically report the photocatalytic degradation of synthetic dyes or phenol halides (Ai et al., 2015; Gu et al., 2018; Aleksandrzak et al., 2017). It lacks information about the efficiency of $\mathrm{rGO} / \mathrm{g}-\mathrm{C}_{3} \mathrm{~N}_{4}$ for degrading CECs like BPA. Moreover, all those papers used a univariate approach for improving the degradation outcome, possibly leading to pseudo-optimal conditions, and not actually the best ones (Bruns et al., 2006). Therefore, the objective of the present work was to perform a multivariate optimization of the rGO/g- $\mathrm{C}_{3} \mathrm{~N}_{4}$ composite synthesis aiming at increasing its photocatalytic activity, employing the response surface methodology and using BPA photodegradation as the response-variable. The composite was characterized and the BPA degradation kinetics and mechanism were studied. Furthermore, photodegradation products were determined and their respective ecotoxicities estimated.

\section{Experimental Section}

\subsection{Materials}

Melamine (99\%, Sigma-Aldrich), graphite powder (99\%, Synth LDT), potassium permanganate (99\%, Synth LDT), and hydrogen peroxide (30\%, Synth LDT), sulfuric acid ( $96 \%$, AppliChem Panreac), hydrochloric acid (37\%, Chemis) and aqueous hydrazine ( $80 \%$, Merck) were used as received.

\subsection{Synthesis of the $\mathrm{g}-\mathrm{C}_{3} \mathrm{~N}_{4}$}

Graphitic carbon nitride $\left(\mathrm{g}-\mathrm{C}_{3} \mathrm{~N}_{4}\right)$ was synthesized by the methodology developed from previous works (Cadan et al., 2021). Two milligrams of melamine were put into a porcelain crucible (model A-45 with cover) and pyrolyzed in a muffle furnace (EDG 7000 coupled to an EDG heater EDGCON 3P).

Melamine was heated, from room temperature to $50^{\circ} \mathrm{C}$, at a rate of $10^{\circ} \mathrm{C} \mathrm{min}-1$ and held at that temperature for $30 \mathrm{~min}$. Then the powder was heated from 50 to $605^{\circ} \mathrm{C}$ at a rate of $6^{\circ} \mathrm{C} \mathrm{min}^{-1}$. The system remained at that temperature for $183 \mathrm{~min}$. Then, the material was naturally cooled to room temperature.

The collected material was ground in an agate mortar/pestle and transferred to Falcon $®$ tubes $(50 \mathrm{~mL})$ which were kept away from light. The amount of $\mathrm{g}-\mathrm{C}_{3} \mathrm{~N}_{4}$ needed for performing all experiments were produced and homogenized.

\subsection{Synthesis of GrO}

Graphite oxide, GrO, was synthesized by a modified Hummers methodology adapted from Chen et al. (2013) - more details are given in the Supplementary Material. Graphite powder $(1.00 \mathrm{~g})$ was mixed with $70 \mathrm{~mL}$ of concentrated sulfuric acid in a 2-L beaker. To this mixture, $9.00 \mathrm{~g}$ of potassium permanganate were added. The system was heated to $40{ }^{\circ} \mathrm{C}$ and magnetically stirred for $40 \mathrm{~min}$. Then, $150 \mathrm{~mL}$ of ultrapure water was poured into it. Finally, $500 \mathrm{~mL}$ of ultrapure 
water were added to the flask. It was magnetically stirred for 15 min more and $10.0 \mathrm{~mL}$ of concentrated hydrogen peroxide $\left(10 \mathrm{~mol} \mathrm{~L}^{-1}\right)$ were slowly added.

This mixture was magnetically stirred for $20 \mathrm{~min}$ and vacuum filtered. The material was suspended in $250 \mathrm{~mL}$ of hydrochloric acid $1.0 \mathrm{~mol} \mathrm{~L}^{-1}$ and vacuum filtered again. The amount of synthesized GrO required for all experiments was prepared and homogenized. The solid was previously frozen, grounded, and dialyzed with a membrane capable of removing ions from 8,000 to $14,000 \mathrm{Da}$. The external solution was renovated every $2 \mathrm{~h}$ during the first day, every $4 \mathrm{~h}$ during the second one, and then every $12 \mathrm{~h}$ thereafter, until the spent water $\mathrm{pH}$ matched the one of ultrapure water $(\mathrm{pH}$ meter Marconi PA 200). The purified material was air-dried and lyophilized for six days. This material was ground into an agate mortar/pestle and transferred to Falcon ${ }^{\circledR}$ tubes $(50 \mathrm{~mL})$ which were also kept away from light.

\subsection{Preparation of the $\mathrm{rGO} / \mathrm{g}-\mathrm{C}_{3} \mathrm{~N}_{4}$}

The composite was prepared by a sonochemical route. Required amounts of $g-\mathrm{C}_{3} \mathrm{~N}_{4}$ and $\mathrm{GrO}$ were weighed to prepare $1.0 \mathrm{~g} \mathrm{~L}^{-1}$ suspensions. Those suspensions were sonicated in parallel with the aid of two ultrasound (tip) devices (BRANSON model 450 and 550, for $\mathrm{GO}$ and $\mathrm{g}-\mathrm{C}_{3} \mathrm{~N}_{4}$, respectively) with power of $14 \mathrm{~W}$ (3 s on, $7 \mathrm{~s}$ off) for $1.5 \mathrm{~h}$. The suspensions were then mixed and magnetically stirred and the $\mathrm{pH}$ was adjusted to 3.0 by the addition of $\mathrm{H}_{2} \mathrm{SO}_{4} 3.0$ mol $\mathrm{L}^{-1}$. After $20 \mathrm{~min}$, the mixture was sonicated again by the same routine for a specific time. To the sonicated mixture, a certain amount of hydrazine was added. That mixture was refluxed at $98{ }^{\circ} \mathrm{C}$ for $24 \mathrm{~h}$. That suspension was naturally cooled down to room temperature and vacuum filtered through $0.45 \mu \mathrm{m}$ pore diameter cellulose acetate membranes. The composite was air-dried during $24 \mathrm{~h}$, away from light, grounded using an agate mortar/pestle, and stored in 1.5-mL Eppendorf $\circledast$ tubes.

\subsection{Optimization of the $\mathrm{rGO} / \mathrm{g}-\mathrm{C}_{3} \mathrm{~N}_{4}$ synthesis}

The response surface methodology (RSM) was used for optimizing the composite synthesis (Bruns et al., 2006). The response-variable was BPA degradation. For more details, please check the Supplementary Material.

Initially, a $2^{3}$ full factorial design (in duplicate) was performed. Three factors were studied: weight percentage of GrO in the mixture prior to reduction (\% $\mathrm{GrO}$ ), the mixture sonication time, and the $\mathrm{N}_{2} \mathrm{H}_{4}$ :GrO weight ratio.

Second, based on the obtained results, a polynomial was adjusted to the data and a set of experiments (according to Equation SM4) were performed along the path of steepest ascent, i.e., towards increasing BPA degradation.

Finally, over the region with the greatest BPA degradations, a central composite design (CCD) was performed. Another polynomial was adjusted to the data. The maximum of that polynomial estimates the best synthetic conditions that would maximize BPA degradation. An analysis of variance (ANOVA) was performed to check the fitting of the model generated.

\subsection{Characterizations}

For the precursors and the optimized composite, X-ray diffraction (XRD), Fourier transform infrared spectrophotometry (FTIR), $\mathrm{N}_{2}$ physisorption using the Brunnauer-Emmett-Teller (BET) isotherm, dynamic light scattering - zeta potentials (ZP), scanning electron microscopy with field emission gun (SEM-FEG), energy dispersive spectroscopy (EDS), diffuse reflectance spectroscopy (DRS) with the Tauc plot approach (Khan et al., 2017), and elemental analysis (CHNS) were performed, as described in the Supplementary Material.

\subsection{Photodegradation experiments}


Photodegradation experiments were performed in a 250-mL, temperature-controlled open-jacketed reactor maintained at $20^{\circ} \mathrm{C}$. Typically, $100 \mathrm{~mL}$ of BPA $100 \mu \mathrm{g} \mathrm{L}^{-1}$ at $\mathrm{pH} 6.0$ (adjusted with aqueous ammonia) and $5.0 \mathrm{mg}$ of catalyst (composite) were put into the reactor and kept under magnetic stirring and air bubbling (approximately $270 \mathrm{~mL} \mathrm{~min}^{-1}$ ) in the dark for $30 \mathrm{~min}$. Then, a black light blue (BLB) lamp (Empalux®, $25 \mathrm{~W}$ ) placed $15 \mathrm{~cm}$ over the suspension surface was turned on for $60 \mathrm{~min}$. Afterwards, the irradiated suspension was filtered through $0.45 \mu \mathrm{m}$ pore diameter cellulose acetate membranes, stored in amber flasks, and kept in the fridge $\left(5^{\circ} \mathrm{C}\right)$ until the extraction step. Adsorption and photolysis experiments were performed in the same manner, except for the absence of light and catalyst, respectively.

\subsection{Extraction step and HPLC analyses}

Extraction was performed by the vortex-assisted liquid-liquid microextraction (VALLME) technique, based on Yantzi et al. (2010). To a glass tube, containing $10.0 \mathrm{~mL}$ of sample, $100 \mu \mathrm{L}$ of $n$-octanol were added without spraying it into the bulk of the sample. The tube was vortex-stirred at 3,800 rpm for $2.5 \mathrm{~min}$ and centrifuged with a relative centrifugal force (RCF) of $1,264 \mathrm{~g}$ at $25^{\circ} \mathrm{C}$ for $20 \mathrm{~min}$. The organic phase was collected with a liquid chromatographic syringe $(25 \mu \mathrm{L}, \mathrm{Hamilton}$ series 700 with fused needle), placed in a $100-\mu \mathrm{L}$ insert inside an $1.5-\mathrm{mL}$ amber chromatographic vial.

HPLC analyses were performed in a Shimadzu chromatograph equipped with a LC-20AT single pump, manual injection by a six-port valve ( $20 \mu \mathrm{L}$ of loop injection), CBM-20A controller powered by LCsolutions ${ }^{\circledR}$ software, DGU-20A ${ }_{5}$ degasser, and SPD-20A UV-vis detector. A Luna ${ }^{\circledR} 5 \mu \mathrm{m}$ C8(2) $100 \AA$, $150 \times 4.6$ mm, LC column was used. Mobile phase was 1:1 acetonitrile and water with $1 \%$ acetic acid. Chromatographic conditions were: injection volume $20 \mu \mathrm{L}$, reversed mode of elution, isocratic mode, flow $1.00 \mathrm{~mL} \mathrm{~min}^{-1}$, detection at $230 \mathrm{~nm}$, total run time $8 \mathrm{~min}$, and BPA retention time $5.3 \mathrm{~min}$.

\subsection{Kinetic and scavenging experiments}

Degradation kinetics experiments (optimized composite) were performed as described in item 2.7, except for using $10.0 \mathrm{mg}$ of the catalyst instead of $5.0 \mathrm{mg}$. All experiments were randomly performed in triplicate. Experiments with scavengers (2.0 mmol L-1 each) were also performed as described by Wang et al. (2019), for irradiation periods of $60 \mathrm{~min}$. The scavengers were added just before the BLB lamp was turned on (Table 1).

Table 1

- Scavengers and respective inhibited species

\begin{tabular}{|ll|}
\hline Scavenger & Inhibited species \\
\hline propan-2-ol (IPA) & hydroxyl radical $(\bullet \mathrm{OH})$ \\
\hline benzoquin-1,4-one (BQ) & superoxide radical $\left(\mathrm{O}_{2}{ }^{\bullet-}\right)$ \\
\hline potassium iodide (KI) & holes in the valence band $\left(\mathrm{h}_{\mathrm{BV}}^{+}\right)$ \\
\hline
\end{tabular}

\subsection{Identification of the degradation products and ecotoxicity estimative}

The experiments were performed in a Shimadzu LC-MS/MS equipment: LC-20AD Prominence Series UFLC pumps coupled to a Brucker Daltonics Esquire 6000 Ion Trap (IT) equipped with an electrospray ion source (ESI) source. The analyses conditions were: column x-TERRA MS (WATERS ${ }^{\mathrm{TM}}$ ) $5.0 \mu \mathrm{m} 150 \cdot 2.1 \mathrm{~mm}$, gradient elution with $0.05 \%$ ammonium hydroxide in water (A) and $0.05 \%$ ammonium hydroxide in acetonitrile (B) from $20 \%$ (B) to $90 \%$ (B) in $10 \mathrm{~min}$, hold for $2 \mathrm{~min}$, then to $20 \%$ in $15 \mathrm{~min}$, flow rate $0.250 \mathrm{~mL} \mathrm{~min}^{-1}$, injection volume $15 \mu \mathrm{L}$. The mass spectrometer conditions were: negative ionization mode, scan mode in the range of $50-500 \mathrm{Da}$, dry gas flow rate $8.0 \mathrm{~L} \mathrm{~min}^{-1}$, nebulizer $20 \mathrm{psi}$, dry temperature $300^{\circ} \mathrm{C}$, capillary voltage $3,500 \mathrm{~V}$. Ecotoxicities were estimated using the freeware Ecological Structure-Activity Relationships (ECOSAR) 2.0. 


\section{Results And Discussion}

\subsection{Pre-optimization experiments (Zeta potential determination)}

Zeta potential (ZP) was measured at different $\mathrm{pH}$ values in order to determine the $\mathrm{pH}$ in which the precursors had opposite charges, since the critical steps of the composite formation is the electrostatic agglomeration of pre-formed particles. At pH 3.0, the surface charge of $\mathrm{g}-\mathrm{C}_{3} \mathrm{~N}_{4}$ and the exfoliated GrO (called graphene oxide, GO) are approximately + 7.96 and $-32.7 \mathrm{mV}$, respectively, as shown in Figure SM1. That $\mathrm{pH}$ value was used in all syntheses.

\subsection{Optimization of the formation of $\mathrm{rGO} / \mathrm{g}-\mathrm{C}_{3} \mathrm{~N}_{4}$}

Initially, a $2^{3}$ (3 factors, 2 levels) full factorial design in duplicate was performed, generating 16 experiments, as shown in Table SM1. The estimated experimental error was 1.9\% (Equation SM2). That error was low as it encompasses several steps (catalyst synthesis, photocalytic experiments, extraction, and HPLC analyses).

A first-order polynomial model (Equation 1) was adjusted to the results of these first experimental design, in which $x_{1}, x_{2}$, and $x_{3}$ are: weight percentage of $\mathrm{GrO}$ in the mixture prior to reduction ( $\% \mathrm{GrO}$ ), the mixture sonication time, and the $\mathrm{N}_{2} \mathrm{H}_{4}: \mathrm{GrO}$ weight ratio, respectively, in coded factors (Equation SM1).

$$
\begin{aligned}
\operatorname{Removal}(\%) & =23.5+5.25 x_{1}-2.45 x_{2}+5.20 x_{1} x_{2}+6.32 x_{1} x_{3} \\
& \pm 0.465 \pm 0.930 \pm 0.930 \pm 0.930 \quad \pm 0.930
\end{aligned}
$$

Main and interaction effects, along with their statistical significance (95\% confidence interval), are presented in Figure SM2. It is possible to observe that the GrO amount and the sonication time were statistically significant, as well as the interaction between them. Increasing GrO amount causes an increment in the answer just as decreasing sonication time does. This might happen because increasing the $\mathrm{GrO}$ amount means increasing the number of electrons acceptors in the material, what makes it possible extended charge separation; meanwhile, decreasing sonication time also decreases the exfoliation of the formed composite, what would cause $\mathrm{g}-\mathrm{C}_{3} \mathrm{~N}_{4}$ to separate itself from rGO (instead of a true composite, one would simply get a physical mixture). Although the interaction between GrO amount and $\mathrm{GrO}: \mathrm{N}_{2} \mathrm{H}_{4}$ weight ratio was statistically significant, the GrO: $\mathrm{N}_{2} \mathrm{H}_{4}$ weight ratio factor itself was not statistically significant within the studied levels. This might mean that, in both levels, hydrazine was in excess. Thus, the amount of hydrazine was set at its lower level in the following experiments.

The experimental conditions with which the best BPA removal was achieved, along the path of steepest ascent (Table SM2), were used as the central point of a CCD (Table SM3). The model proposed for de CCD is shown in Eq. (2).

$$
\begin{aligned}
\operatorname{Removal}(\%)= & 61.0-8.65 x_{1}-2.52 x_{2}+4.73 x_{1} x_{2}-8.98 x_{1}^{2}-7.83 x_{2}^{2}+5.78 x_{1}^{3} \\
& \pm 0.917 \pm 1.78 \pm 0.562 \pm 0.794 \quad \pm 0.669 \quad \pm 0.669 \pm 1.12
\end{aligned}
$$


Equation 2 generates the surface in Figure SM3. The model was well adjusted according to an ANOVA (Table SM4) and the Fisher's statistics. The respective maximum (optimum synthetic conditions) could be estimated: $x_{1}=-0.039$ and $x_{2}=$ -0.26 , i.e., $\% \mathrm{GrO}=15 \%$ and sonication time $=7 \mathrm{~min}$ e $20 \mathrm{~s}$, respectively. One can observe the improvement achieved regarding BPA removal, which varied from $24 \%$ (central point conditions, initial $2^{3}$ full factorial design) to $65 \%$ (optimal conditions, CCD) - a three-fold increase, approximately. All of the following results were obtained with the optimized material.

\subsection{Characterization}

According to the XRD analysis (Fig. 1) both precursor materials were formed and the composite crystalline structure did not differ from the one of $\mathrm{g}-\mathrm{C}_{3} \mathrm{~N}_{4}$, agreeing with Gu et al. (2018) and Liu et al. (2016). That can be attributed to: (a) rGO produces low-intensity signals in XRD; and (b) low rGO content in the composite, small enough not to change the g- $\mathrm{C}_{3} \mathrm{~N}_{4}$ crystalline structure.

GrO is characterized by the single peak at $11.6^{\circ}$ related to $\left(\begin{array}{ll}1 & 0\end{array}\right)$, matching JCPDS file $75-2078$, in accordance with the literature (Aleksandrzak et al., 2017; Blanton and Majumdar, 2013; Chen et al., 2017; He et al., 2018). g- $\mathrm{C}_{3} \mathrm{~N}_{4}$ presents two major peaks at $13.2^{\circ}\left(\begin{array}{lll}1 & 0 & 0\end{array}\right)$ and $26.6^{\circ}\left(\begin{array}{lll}0 & 0 & 2\end{array}\right)$, and minor peaks at $44.6^{\circ}\left(\begin{array}{lll}2 & 0 & 0\end{array}\right)$ and $56.4^{\circ}\left(\begin{array}{lll}0 & 0 & 4\end{array}\right)$, matching JCPDS file 871526. Those results were also reported by Cao et al. (2013), Ma et al. (2014), and Sun et al. (2017).

The microstructures (Fig. 2) suggest that precursors and composite particles have no particular habit, within a micrometric scale. The materials in the composite are undistinguishable, being clusters of precursor layers. The observed lamellar clustering (Figs. 5c) could be associated with the synthesis based on the self-assembling of bidimensional precursors. $\mathrm{g}-\mathrm{C}_{3} \mathrm{~N}_{4}$ and GrO specific surface areas (SA) were approximately 25.8 and $160 \mathrm{~m}^{2} \mathrm{~g}^{-1}$, respectively. The SA of the optimized material was $85.9 \mathrm{~m}^{2} \mathrm{~g}^{-1}$, while $\mathrm{g}-\mathrm{C}_{3} \mathrm{~N}_{4}$ under identical exfoliation conditions (no GrO) was $31.7 \mathrm{~m}^{2} \mathrm{~g}^{-1}$, indicating that rGO alters the specific surface area of the composite, probably by unpacking $g-\mathrm{C}_{3} \mathrm{~N}_{4}$ layers due an electrostatic effect. As a matter of fact, the expected SA for the simple mixture of $\mathrm{g}-\mathrm{C}_{3} \mathrm{~N}_{4}$ and rGO in the same content (16\% rGO) is $47 \mathrm{~m}^{2} \cdot \mathrm{g}^{-1}$, confirming the SA increasing effect.

The $\mathrm{pH}$ of the composite formation (set in 3.0) also can be associated to the SA since pH affects how well the exfoliation and agglomeration of the material occur (Silva et al., 2017). The ZP curve (Figure SM4) of the composite shows that the optimized material follows the same profile of pristine $\mathrm{g}-\mathrm{C}_{3} \mathrm{~N}_{4}$, previously shown (Figure SM1).

By the EDS results (Figure SM5), one can observe that pure $\mathrm{g}-\mathrm{C}_{3} \mathrm{~N}_{4}$ was formed, considering that the employed solidphase synthesis required only one reagent. The small content of impurities (1.92\%) is derived from the sample holder. Apparently, the contact with atmospheric air during pyrolysis allowed a partial oxidation during the annealing. That would explain the presence of oxygen in the EDS analyses.

GrO (Figure SM6) was still impregnated with a small amount of sulfur, chlorine, and manganese, even after the exhaustive purification. Nevertheless, as that residual contamination is small (2.21\%), the material was considered suited for the next synthetic steps. Again, $1.19 \%$ of impurities came from the sample holder. Finally, looking at the optimized material (Fig. 3), it did not show impurities, except for 3.25\% from the sample holder.

Aiming at estimating the rGO content in the synthesized photocatalyst, CHNSO analyses were performed. First, the g$\mathrm{C}_{3} \mathrm{~N}_{4}$ precursor was analyzed and the nitrogen content was determined. Second, the composite was also analyzed and, 
using that previous nitrogen content, the amount of $\mathrm{g}-\mathrm{C}_{3} \mathrm{~N}_{4}$ was calculated. By subtracting the $\mathrm{g}-\mathrm{C}_{3} \mathrm{~N}_{4}$ mass from the composite one, the rGO mass was calculated. Therefore, the rGO content in the composite was estimated as approximately $4.0 \%$.

Precursors and the optimized material were also characterized by their FTIR spectra (Fig. 4, Table 2). Bands were identified in accordance with the work of Aleksandrzak et al. (2017). Reduced graphene oxide was almost free from oxygen and it was mainly composed of carbon and hydrogen (small electronegativity difference). Therefore, the spectrum of the optimized material is similar to the one of $\mathrm{g}-\mathrm{C}_{3} \mathrm{~N}_{4}$, as the magnet dipoles of the chemical bonds are not high enough for coupling with the infrared waves emitted by the source.

Table 2 - Attribution of the bands from the FTIR analysis

\begin{tabular}{ccr}
\hline Band & $\begin{array}{c}\text { Wave number } \\
\left(\mathrm{cm}^{-1}\right)\end{array}$ & Attribution \\
\hline I (a) & 1057 & stretching vibration of C-O bonds of alkoxy groups \\
\hline II (a) & 1620 & stretching and bending vibration of OH groups \\
\hline III (a) & 1726 & stretching vibration of C=O of carboxyl groups \\
\hline IV (a) & 3320 & Stretching of the O-H bonds in hydroxyl groups \\
\hline I (b) & 806 & breathing mode of the triazine units \\
\hline II (b) & $1234 ; 1313 ; 1398$ & stretching modes of C-N bond in heterocycles \\
\hline III (b) & 1625 & stretching mode of C=N bonds \\
\hline IV (b) & 3130 & stretching modes of secondary and primary amines \\
\hline
\end{tabular}

Reduced graphene oxide changes from bright yellow g- $\mathrm{C}_{3} \mathrm{~N}_{4}$ to a dark gray material, which explains the lower reflectance of the composite (Fig. 5a). In the DRS analysis, one can observe that the band gap of $\mathrm{g}-\mathrm{C}_{3} \mathrm{~N}_{4}$ did not change significantly by the presence of rGO in the structure (Fig. 5b).

rGO is a conductor species (no significant charge separation) with a transition considered to be direct and allowed ( $r=$ 0.5). Therefore, oxidation reactions are promoted by $\mathrm{g}-\mathrm{C}_{3} \mathrm{~N}_{4}$, suggesting that the improved photocatalytic activity of the material may be due to increased specific surface areas and low recombination rates - charge transfer to rGO (Malagutti et al., 2009).

VB (+ $1.55 \mathrm{eV})$ and $\mathrm{CB}(-1.09 \mathrm{eV})$ potentials for $\mathrm{g}-\mathrm{C}_{3} \mathrm{~N}_{4}$ were estimated by the empiric Equations SM6-8 (Mousavi et al., 2016). As rGO exhibits no significant charge separation (Fig. 5a) and pure g- $\mathrm{C}_{3} \mathrm{~N}_{4}$ and the composite band gaps were almost the same (Fig. 5 b), the estimated band positions for $\mathrm{g}-\mathrm{C}_{3} \mathrm{~N}_{4}$ were considered to be the same for the composite3.4 Degradation kinetics and scavenging tests

Figure 6 presents the BPA degradation kinetics. Both pure $\mathrm{g}-\mathrm{C}_{3} \mathrm{~N}_{4}$ and optimized $\mathrm{rGO} / \mathrm{g}-\mathrm{C}_{3} \mathrm{~N}_{4}$ followed a pseudo-first order behavior, with $k^{\prime}=(0.94 \pm 0.019) \cdot 10^{-2} \mathrm{~min}^{-1}\left(R^{2}=0.981\right)$ and $k^{\prime \prime}=(2.0 \pm 0.083) \cdot 10^{-2} \mathrm{~min}^{-1}\left(R^{2}=0.986\right)$, respectively. Therefore, $\mathrm{rGO} / \mathrm{g}-\mathrm{C}_{3} \mathrm{~N}_{4}$ removed BPA approximately 2.4 times faster than $\mathrm{g}-\mathrm{C}_{3} \mathrm{~N}_{4}$ alone. Dark adsorption and direct photolysis after 90 min, 10.7 and 6.2\%, respectively, also shown in Fig. 3, were much less significant than heterogeneous photocatalysis.

Scavenging tests (Table 3) pointed out that the main species involved in BPA degradation was the superoxide radical (Ji et al., 2013; Wang et al., 2017). It was also possible to observe that holes and hydroxyl radicals were not really important for the degradation of the target molecule. Taking into account the scavenging tests results, the calculated VB and CB potentials, and the necessary potentials for generating $\mathrm{O}_{2}{ }^{\mathbf{-}}$ and ${ }^{\bullet} \mathrm{OH}$ (all of them against the NHE), it becomes clear that aqueous $\mathrm{O}_{2}{ }^{- \text {- }}$ could be easily formed in the presence of the composite, once its CB potential was $-1.09 \mathrm{eV}$ and the reduction potential of $\mathrm{O}_{2}$ into $\mathrm{O}_{2} \mathbf{0}^{-}$is $-0.33 \mathrm{eV}$ (Malagutti et al., 2009), approximately 3 times lower (in absolute values). On the other hand, it is straightforward why $\bullet \mathbf{O H}$ did not play any significant role in the degradation process. The 
oxidation potential of $\mathrm{H}_{2} \mathrm{O}$ into ${ }^{\circ} \mathrm{OH}$ is $+2.80 \mathrm{eV}$ (Bauer and Fallmann, 1997), approximately 2 times higher than the VB potential $(+1.55 \mathrm{eV})$. However, the material is able to oxidize $\mathrm{H}_{2} \mathrm{O}$ into $\mathrm{O}_{2}$, as the VB potential is greater than $+1.23 \mathrm{eV}$ (Zhao et al., 2014). In summary, the BPA degradation mechanism was based on the superoxide radical chemistry, formed when the composite $\mathrm{CB}$ reduces dissolved molecular oxygen.

Table 3 - BPA degradations with scavengers

\begin{tabular}{cc}
\hline Scavenger & Removal (\%) \\
\hline None & 65.0 \\
IPA & 64.5 \\
BQ & 42.0 \\
KI & 60.0 \\
\hline
\end{tabular}

\section{IPA = propan-2-ol; $\mathrm{BQ}=$ benzoquin-1,4-one; $\mathrm{KI}$ = potassium iodide}

\subsection{Degradation Products Identification and Ecotoxicity}

Two major degradation products (DPs) were identified: 4-(2-(3,4-dihydroxyphenyl)propan-2-yl)cyclohexa-3,5-diene-1,2dione (DP1) and 4,4'-(propane-2,2-diyl)bis(cyclohexa-3,5-diene-1,2-dione) (DP2). Their structures are shown in Fig. 7 and their mass spectra are given in Figure SM7. Those molecules were also detected by Kondrakov et al. (2014).

Two concurrent degradation mechanisms were proposed in Fig. 8, as the major oxidizing agent acting in the treatment was the superoxide radical. In path (1), superoxide radical abstracts a proton from BPA (-OH moiety) forming a hydroperoxyl radical. The deprotonated oxygen atom can form a double bond, allowing the hydroperoxyl radical to attack the carbon vicinal to the formed ketone. The added hydroperoxyl radical removes a proton from that carbon, triggering the elimination of water and forming a double bond with the remaining oxygen atom.

In path (2), superoxide radical adds a radicalar oxygen to BPA (vicinal carbon to the $-\mathrm{OH}$ moiety) and a hydroxyl ion is eliminated. The radicalar oxygen can abstract a proton from water forming hydroxyl radical in the process. Therefore, DP1 is formed when BPA reacts by paths (1) and (2); DP2 when BPA reacts only by path (1) or when DP1 undergoes oxidation (Li, Kuo, Weeks Junior, 1979; Lerner et al., 2006).

Figure 9 shows the estimated ecotoxicities of BPA and the proposed DPs by the ECOSAR 2.0 software. $\mathrm{LC}_{50}$ and EC $\mathrm{E}_{50}$ are the concentrations in which a single exposition to a chemical species, during a specific period of time, promotes death or deleterious effects to $50 \%$ of a tested population. On the other hand, $\mathrm{ChV}$ is the chronic value, i.e., the concentration in which a continuous exposition promotes chronic effects (Gupta, 2018). According to the Globally Harmonized System of Classification and Labeling of Chemicals (GHS), the ratio $(\mathrm{R})$ between the acute effect $\left(\mathrm{LC}_{50}\right.$ or $\left.\mathrm{EC}_{50}\right)$ and

the chronic one $(\mathrm{ChV})$ determines the ecotoxicity of a compound: Very toxic $(\mathrm{R} \leq 1)$,

Toxic $(1<\mathrm{R} \leq 10)$, Harmful $(10<\mathrm{R} \leq 100)$, and Not harmful $(\mathrm{R}>100)$ (The United

Nations, 2017).

As expected, BPA was very toxic or toxic to all of the test-organisms, both for acute and chronic exposures. One can see that DP2 was less toxic for all the organisms for both levels of exposure, being even not harmful for fishes within acute level. DP1 was also less harmful than BPA for all the organisms in both levels. Therefore, the proposed treatment is effective for BPA removal because it not just can degrade the BPA molecule but also convert it to less toxic species.

\section{Conclusions}

- The multivariate approach was helpful for determining the conditions in which materials with optimized photocatalytic properties could be synthesized. 
- The use of the sonochemical approach was useful for keeping the experimental conditions reproducible, what is reflected by the low experimental error of the experimental design. It was also helpful for obtaining a material with large specific surface area.

- The use of bisphenol A as model-pollutant at environmental concentrations helped in getting closer-to-real-life treatment conditions, although that makes analytical procedures more challenging.

- Characterizing this kind of composite, in which precursors have similar structures and compositions, is a true challenge because it is hard to notice any differences in a variety of techniques (FTIR, XRD, SEM, etc.).

- Although the analytical signals of rGO were hard to perceive, its presence in the composite could be inferred by the increased specific surface area and the photocatalytic activity of the composite.

- The photocatalytic BPA degradation exhibited a pseudo-first-order kinetics, both for $\mathrm{g}-\mathrm{C}_{3} \mathrm{~N}_{4}$ and the composite. The degradation rate, using the synthesized composite as the photocatalyst, was twice as fast as the one with g- $\mathrm{C}_{3} \mathrm{~N}_{4}$.

- The main oxidizing species generated by the composite was $\mathrm{O}_{2} \mathbf{\bullet}^{-}$, according to the calculated band positions and scavenging tests.

- The synthesized material was able to successfully degrade and partially detoxify BPA in a relatively short period of time.

\section{Declarations}

\section{ETHICAL Approval}

No ethics approval was necessary for this work.

\section{Consent to participate}

All authors gave their consent to participate.

\section{Consent to publish}

All authors gave their consent to this publication.

\section{Authors contributions}

All authors have contributed to this work. Chubraider Xavier wrote the paper and performed the majority of the experiments. Bianca Rebelo Lopes performed the mass spectrometry experiments and wrote the respective part of the Material and Methods section; Caue Ribeiro discussed the ideas with the authors and reviewed the paper; Eduardo Bessa Azevedo discussed the ideas, supervised the work, and reviewed the paper.

\section{Funding}

The authors would like to thank The National Council for Scientific and Technological Development (CNPq), grant \# 140410/2019-8, The Coordination for the Improvement of Higher Education Personnel (CAPES - Finance Code 001), São Paulo Research Foundation (FAPESP), process \# 2018/01258-5 and The Research Network of Nanotechnology Applied to Agribusiness (AgroNano Network/Embrapa, MCTI-SisNano) for financial support.

\section{Competing interests}

There is no conflict or competing interests for this work.

\section{Availability of data and materials}


All data and supplementary materials are available for consult.

\section{ACKNOWLEDGEMENTS}

The authors also thank Professor Quezia Bezerra Cass for making the mass spectrometry analyses possible.

\section{References}

1. Adhikari SP, Pant HR, Kim HJ, Park CH, Kim CS (2015) Deposition of ZnO flowers on the surface of g- $\mathrm{C}_{3} \mathrm{~N}_{4}$ sheets via hydrothermal process. Ceram Int 41(10):12923-12929. DOI:10.1016/j.ceramint.2015.06.134

2. Ai B, Duan X, Sun H, Qiu X, Wang S Metal-free graphene-carbon nitride hybrids for photodegradation of organic pollutants in water. Catal. Today, 258 (2015) Part 2, 668-675. DOI: 10.1016/j.cattod.2015.01.024

3. Aleksandrzak M, Kukulka W, Mijowska E (2017) Graphitic carbon nitride/graphene oxide/reduced graphene oxide nanocomposites for photoluminescence and photocatalysis. Appl Surf Sci 398:56-62.

DOI:10.1016/j.apsusc.2016.12.023

4. Ankley GT, Erickson RJ, Hoff DJ, Mount DR, Lazorchak J, Beaman J, Linton TK (2008) Aquatic life criteria for contaminants of emerging concern: Part I General challenges and recommendations. USA, EPA. https://www.epa.gov/sites/production/files/2015-08/documents/white_paper_

aquatic_life_criteria_for_contaminants_of_emerging_concern_part_i_general_challenges_and_recommendations 1 .pdf (Accessed 02 August 2020)

5. Bauer R, Fallmann H (1997) The photo-Fenton oxidation - A cheap and efficient wastewater treatment method. Res Chem Intermediat 23(4):341-354. DOI:10.1163/156856797X00565

6. Blanton TN, Majumdar D (2013) Characterization of X-ray irradiated graphene oxide coatings using X-ray diffraction, X-ray photoelectron spectroscopy, and atomic force microscopy. Powder Diffr 28 2:68-71.

DOI:10.1017/S0885715613000109

7. Bruns RE, Scaramino IS, Barros Neto B Statistical Design - Chemometrics. First edition, Elsevier: Amsterdam, 422 p., 2006. ISBN-13: 978-0444521811\$4

8. Cadan FM, Ribeiro C, Azevedo EB (2021) Improving g- $\mathrm{C}_{3} \mathrm{~N}_{4}: \mathrm{WO}_{3}$ Z-scheme photocatalytic performance under visible light by multivariate optimization of $\mathrm{g}-\mathrm{C}_{3} \mathrm{~N}_{4}$ synthesis. Appl Surf Sci 537:147904-114917.

DOI:10.1016/j.apsusc.2020.147904

9. Cao S-W, Yuan Y-P, Fang J, Shahjamali MM, Boey FY, Barber J, Loo SCJ, Xue C (2013) In-situ growth of CdS quantum dots on $\mathrm{g}^{-} \mathrm{C}_{3} \mathrm{~N}_{4}$ nanosheets for highly efficient photocatalytic hydrogen generation under visible light irradiation. Int $\mathrm{J}$ Hydrogen Energ 38(3):1258-1266. DOI:10.1016/j.ijhydene.2012.10.116

10. Chen J, Yao B, Li C, Shi G (2013) An improved Hummers method for eco-friendly synthesis of graphene oxide. Carbon 64:225-229. DOI:10.1016/j.carbon.2013.07.055

11. Chen K, Chai Z, Li C, Shi L, Liu M, Xie Q, Zhang Y, Xu D, Manivannan A, Liu Z (2016) Catalyst-free growth of threedimensional graphene flakes and graphene/g- $\mathrm{C}_{3} \mathrm{~N}_{4}$ composite for hydrocarbon oxidation. ACS Nano 10(3):36653673. DOI:10.1021/acsnano.6b00113

12. Chen Q, Cai D, Zhan H (2017) Construction of reduced graphene oxide nanofibers and cobalt sulfide nanocomposite for pseudocapacitors with enhanced performance. J Alloy Compd 706:126-132. DOI:10.1016/j.jallcom.2017.02.189

13. Duan H, Wang D, Li Y (2015) Green chemistry for nanoparticle synthesis. Chem Soc Rev 44:16, 5778-5792. DOI:10.1039/C4CS00363B

14. Gu Y, Yu Y, Zou J, Shen T, Xu Q, Yue X, Meng J, Wang J (2018) The ultra-rapid synthesis of rGO/g- $\mathrm{C}_{3} \mathrm{~N}_{4}$ composite via microwave heating with enhanced photo-catalytic performance. Mater Lett 232:107-109. 
DOI:10.1016/j.matlet.2018.08.077

15. Gupta PK (Ed.) General toxicology. In: Illustrated Toxicology: With study questions. 1. Ed. Academic Press: London, UK, 2018,1-65. ISBN 978-0-12-813213-5

16. Hao Q, Hao S, Niu X, Li X, Chen D, Ding H (2017) Enhanced photochemical oxidation ability of carbon nitride by $\pi-\pi$ stacking interactions with graphene. Chinese J Catal 38(2):278-286. DOI:10.1016/S1872-2067(16)62561-5

17. He H, Huang L, Zhong Z, Tan S (2018) Constructing three-dimensional porous graphene-carbon quantum dots/g$\mathrm{C}_{3} \mathrm{~N}_{4}$ nanosheet aerogel metal-free photocatalyst with enhanced photocatalytic activity. Appl Surf Sci 441:31, 285294. DOI:10.1016/j.apsusc.2018.01.298

18. Ji H, Chang F, Hu X, Qin W, Shen J (2013) Photocatalytic degradation of 2,4,6-trichlorophenol over g- $\mathrm{C}_{3} \mathrm{~N}_{4}$ under visible light irradiation. Chem Eng J 218:183-190. DOI:10.1016/j.cej.2012.12.033

19. Khan H, Rigamonti MG, Patience GS, Boffito DC (2017) Spray dried $\mathrm{TiO}_{2} / \mathrm{WO}_{3}$ heterostructure for photocatalytic applications with residual activity in the dark. Appl Catal B-Environ 226:311-323. DOI:10.1016/j.apcatb.2017.12.049

20. Kondrakov AO, Ignatev AN, Frimmel FH, Bräse S, Horn H, Revelsky Al. Formation of genotoxic quinones during bisphenol A degradation by TiO2 photocatalysis and UV photolysis: A comparative study. Appl. Catal. B-Environ., 160-161 (2014), 106-114. DOI: 10.1016/j.apcatb.2014.05.007

21. Lerner H-W, Margraf G, Kretz T, Schiemann O, Bats J, Dürner G, Fabrizi de Biani, F, Zanello P, Bolte M, Wagner M (2006) Redox behaviour of pyrazolyl-substituted 1,4-dihydroxyarenes: Formation of the corresponding semiquinones, quinhydrones and quinones. Z Naturforsch B 61:252-264. DOI:10.1515/znb-2006-0304

22. Li KY, Kuo CH, Weeks Junior JL (1979) A kinetic study of ozone-phenol reaction in aqueous solutions. AIChE J 25(4):583-591. DOI:10.1002/aic.690250403

23. Liu Q, Guo Y, Chen Z, Zhang Z, Fang X (2016) Constructing a novel ternary Fe(III)/graphene/g- $\mathrm{C}_{3} \mathrm{~N}_{4}$ composite photocatalyst with enhanced visible-light driven photocatalytic activity via interfacial charge transfer effect. Appl Catal B-Environ 183:231-241. DOI:10.1016/j.apcatb.2015.10.054

24. Ma TY, Tang Y, Dai S, Qiao SZ (2014) Proton-functionalized two-dimensional graphitic carbon nitride nanosheet: An excellent metal-/label-free biosensing platform. Small 10:12, 2382-2389. DOI:10.1002/smll.201303827

25. Malagutti AR, Mourão HAJL, Garbin JR, Ribeiro C (2009) Deposition of $\mathrm{TiO}_{2}$ and $\mathrm{Ag}: \mathrm{TiO}_{2}$ thin films by the polymeric precursor method and their application in the photodegradation of textile dyes. Appl Catal B-Environ 90:205-212. DOI:10.1590/1980-5373-MR-2015-0358

26. Meng X, Zhang Z (2018) Two dimensional graphitic materials for photoelectrocatalysis: A short review. Cat Today 315:2-8. DOI:10.1016/j.cattod.2018.03.015

27. Moma J, Baloyi J Modified titanium dioxide for photocatalytic applications. In: KHAN, S. B.; AKHTAR, K (Org.) Photocatalysts: Applications and attributes. First Edition, IntechOpen Limited: London, 156 p., 2019. ISBN: 978-178985-476-3

28. Mousavi M, Habibi-Yangjeh A, Abitorabi M (2016) Fabrication of novel magnetically separable nanocomposites using graphitic carbon nitride, silver phosphate and silver chloride and their applications in photocatalytic removal of different pollutants using visible-light irradiation. J Colloid Interf Sci 480:218-231. DOI:10.1016/j.jcis.2016.07.021

29. Mural PKS, Sharma M, Madras G, Bose S (2015) A critical review on in situ reduction of graphene oxide during preparation of conducting polymeric nanocomposites. RSC Advances 5:41, 32078-32087.

DOI:10.1039/C5RA02877A

30. Nikokavoura A, Trapalis $\mathrm{C}$ (2017) Alternative photocatalysts to $\mathrm{TiO}_{2}$ for the photocatalytic reduction of $\mathrm{CO}_{2}$. Appl Surf Sci 391:149-174. DOI:10.1016/j.apsusc.2016.06.172

31. Nikokavoura A, Trapalis $\mathrm{C}$ (2018) Graphene and $\mathrm{g}-\mathrm{C}_{3} \mathrm{~N}_{4}$ based photocatalysts for $\mathrm{NO}_{\mathrm{x}}$ removal: A review. Appl Surf Sci 430:18-52. DOI:10.1016/j.apsusc.2017.08.192

Page $12 / 17$ 
32. Obregón $\mathrm{S}$, Colón $\mathrm{G}$ Improved $\mathrm{H}_{2}$ production of $\mathrm{Pt}-\mathrm{TiO}_{2} / \mathrm{g}-\mathrm{C}_{3} \mathrm{~N}_{4}-\mathrm{MnO}_{\mathrm{x}}$ composites by an efficient handling of photogenerated charge pairs. Appl Catal B-Environ 144 (2014), 775-782. DOI:10.1016/j.apcatb.2013.07.034

33. Qian J, Yan J, Shen C, Xi F, Dong X, Liu J (2018) Graphene quantum dots-assisted exfoliation of graphitic carbon nitride to prepare metal-free zero-dimensional/two-dimensional composite photocatalysts. J Mater Sci 53:1210312114. DOI:10.1007/s10853-018-2509-8

34. Reddy PVL, Kim K-H, Kavitha B, Kumar V, Raza N, Kalagara S (2018) Photocatalytic degradation of bisphenol A in aqueous media: A review. J Environ Manage 213:189-205. DOI:10.1016/j.jenvman.2018.02.059

35. Rochester JR, Bolden AL, Kwiatkowski CF (2018) Prenatal exposure to bisphenol A and hyperactivity in children: A systematic review and meta-analysis. Environ Int 114:343-356. DOI:10.1016/j.envint.2017.12.028

36. Silva GT, Carvalho KT, Lopes OF, Ribeiro $\mathrm{C} \mathrm{g}-\mathrm{C}_{3} \mathrm{~N}_{4} / \mathrm{Nb}_{2} \mathrm{O}_{5}$ heterostructures tailored by sonochemical synthesis: Enhanced photocatalytic performance in oxidation of emerging pollutants driven by visible radiation. Appl Catal BEnviron 216 (2017), 70-79. DOI:10.1016/j.apcatb.2017.05.038

37. Sun B-W, Yu H-Y, Yang Y-J, Li H-J, Zhai C-Y, Qian D-J, Chen M (2017) New complete assignment of X-ray powder diffraction patterns in graphitic carbon nitride using discrete Fourier transform and direct experimental evidence. Phys Chem Chem Phys 19:38, 26072-26084. DOI:10.1039/C7CP05242A

38. The United Nations. Annex 9: Guidance on Hazards to the Aquatic Environment. 2017. <https://www.unece.org/fileadmin/DAM/trans/danger/publi/ghs/ghs_rev07/English/12e_annex9.pdf>. (Accessed 04 december 2020)

39. UNESCO. WWAP (UNESCO World Water Assessment Programme). The United Nations. World Water Development Report 2019: Leaving No One Behind. Paris, UNESCO (2019) https://en.unesco.org/themes/watersecurity/wwap/wwdr/2019, 2019 (Accessed 02 August 2020)

40. Wan J, Pu,; Wang R, Liu E, Du X, Bai X, Fan J, Hu X (2018) A facile dissolution strategy facilitated by $\mathrm{H}_{2} \mathrm{SO}_{4}$ to fabricate a $2 \mathrm{D}$ metal-free $\mathrm{g}-\mathrm{C}_{3} \mathrm{~N}_{4} / \mathrm{rGO}$ heterojunction for efficient photocatalytic $\mathrm{H}_{2}$ production. Int $\mathrm{J}$ Hydrogen Energ 43:14, 7007-7019. DOI:10.1016/j.ijhydene.2018.02.134

41. Wang Y, Cao D, Liu M, Zhao X (2017) Insights into heterogeneous catalytic activation of peroxymonosulfate by Pd/g$\mathrm{C}_{3} \mathrm{~N}_{4}$ : The role of superoxide radical and singlet oxygen. Catal Commun 102:85-88.

DOI:10.1016/j.catcom.2017.08.016

42. Wang Y, Wang Y, Yu L, Wang J, Du B, Zhang X (2019) Enhanced catalytic activity of templated-double perovskite with 3D network structure for salicylic acid degradation under microwave irradiation: Insight into the catalytic mechanism. Chem Eng J 368:115-128. DOI:10.1016/j.cej.2019.02.174

43. Wassenaar PNH, Trasande L, Legler J Systematic review and meta-analysis of early-life exposure to bisphenol A and obesity-related outcomes in rodents. Environ. Health Perspect.,125 (2017) 10, 106001-1-106001-15. DOI: 10.1289/EHP1233

44. Yiantzi E, Psillakis E, Tyrovola K, Kalogerakis N Vortex-assisted liquid-liquid microextraction of octylphenol, nonylphenol and bisphenol-A. Talanta, 80, (2010) 5, 2057-2062. DOI: 10.1016/j.talanta.2009.11.005

45. Zhao J, Wang X, Xu Z, Loo JSC (2014) Hybrid catalysts for photoelectrochemical reduction of carbon dioxide: A prospective review on semiconductor/metal complex co-catalyst systems. J Mater Chem 2 37:15228-15233. DOI:10.1039/C4TA02250E

46. Ziv-Gal A, Flaws JA (2016) Evidence for bisphenol A-induced female infertility: A review (2007-2016). Fertil Steril 106(4):827-856. DOI:10.1016/j.fertnstert.2016.06.027

\section{Figures}




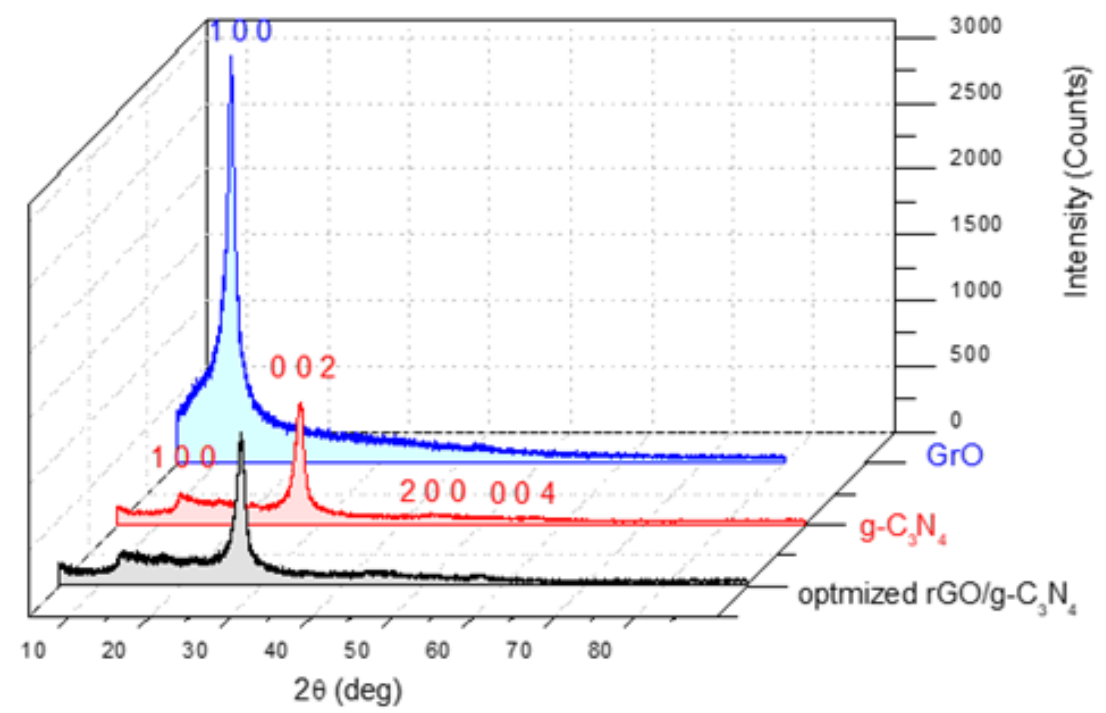

Figure 1

XRD of graphite oxide (GrO), graphitic carbon nitride (g-C3N4), and the composite in optimized conditions

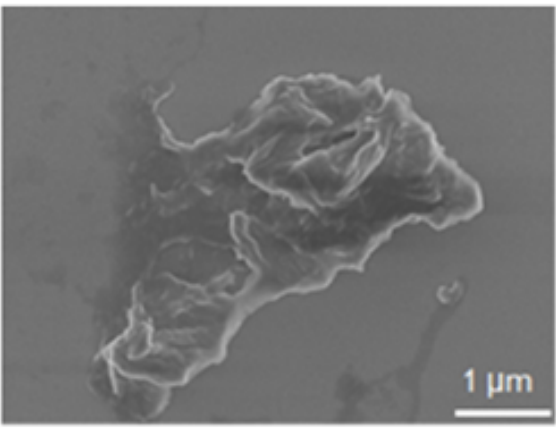

(a)

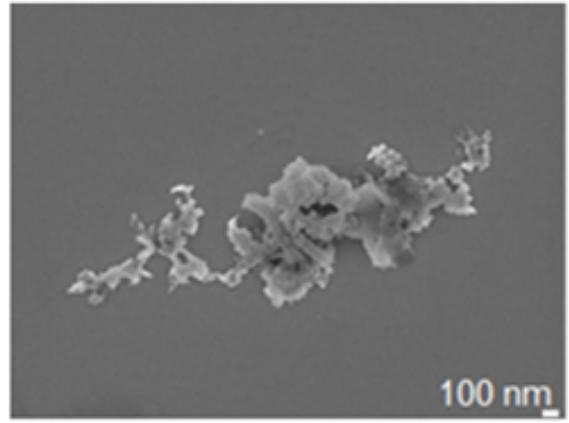

(b)

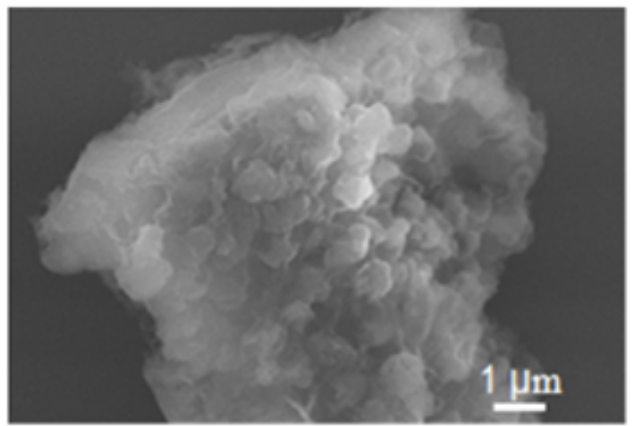

(c)

\section{Figure 2}

Scanning Electron Microscopy of (a) GrO (b) g-C3N4 (c) optimized rGO/g-C3N4 


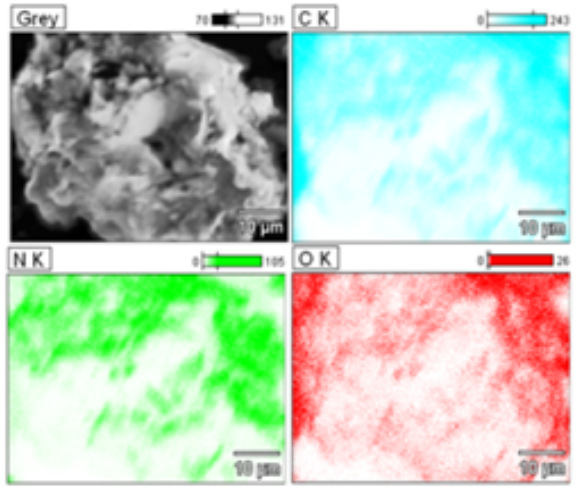

(a)

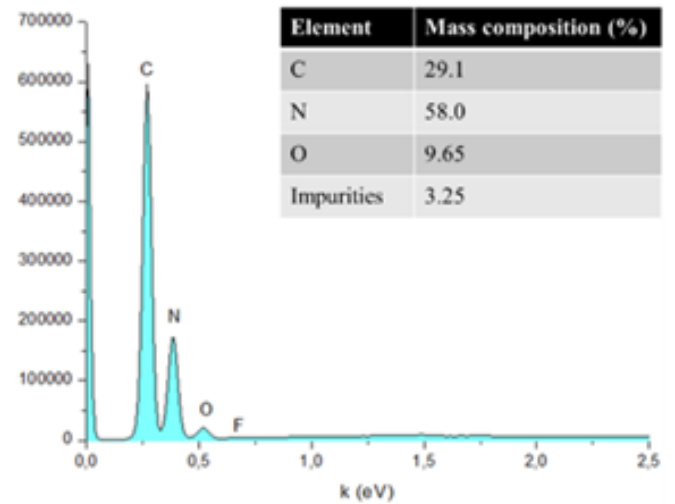

(b)

Figure 3

EDS (a) distribution and (b) spectrum for the optimized rGO/g-C3N4

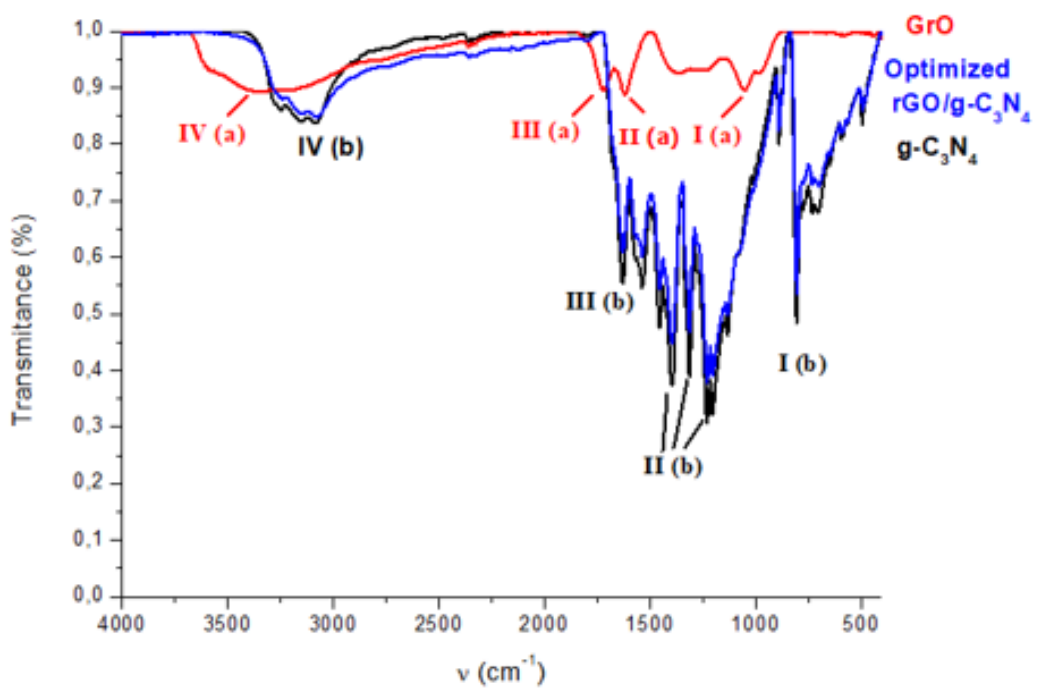

Figure 4

FTIR spectra of precursors and the optimized composite

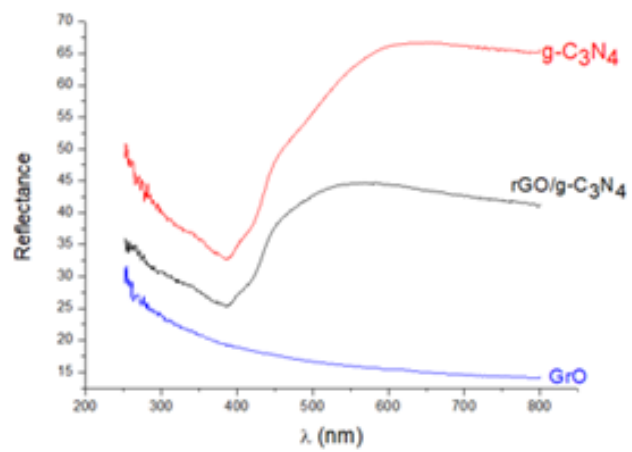

(a)

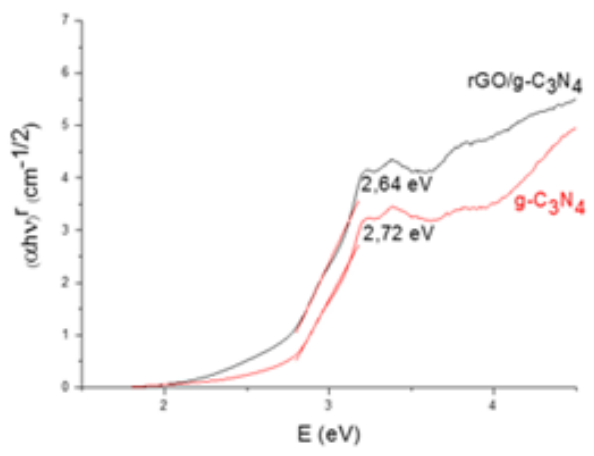

(b)

Figure 5

(a) DRS and (b) Tauc Plot of precursors and the optimized composite 


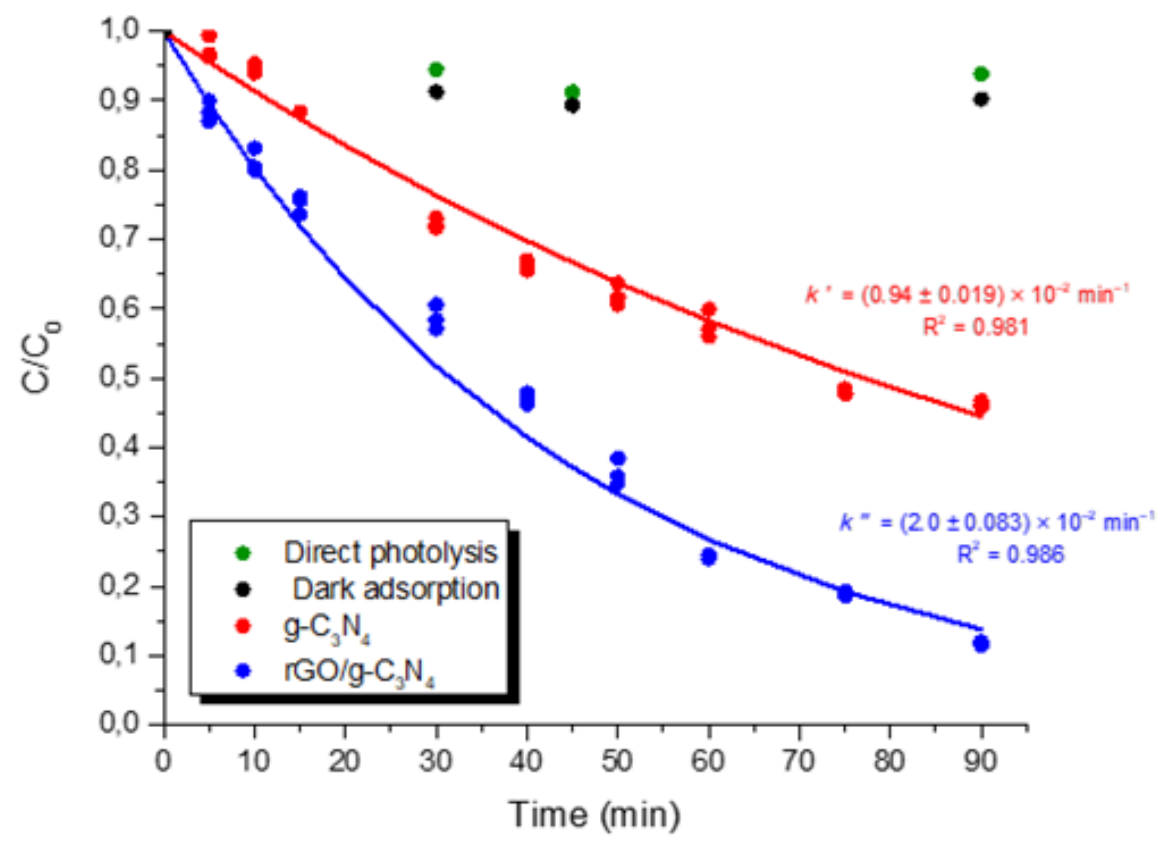

Figure 6

BPA Removal kinetics<smiles>CC(C)(c1ccc(O)cc1)c1ccc(O)cc1</smiles>

(a)<smiles>CC(C)(C1=CC(=O)C(=O)C=C1)c1ccc(O)c(O)c1</smiles>

(b)<smiles>CC(C)(C1=CC(=O)C(=O)C=C1)C1=CC(=O)C(=O)C=C1</smiles>

(c)

Figure 7

a) BPA structure and the proposed ones for (b) DP1 and (c) DP2

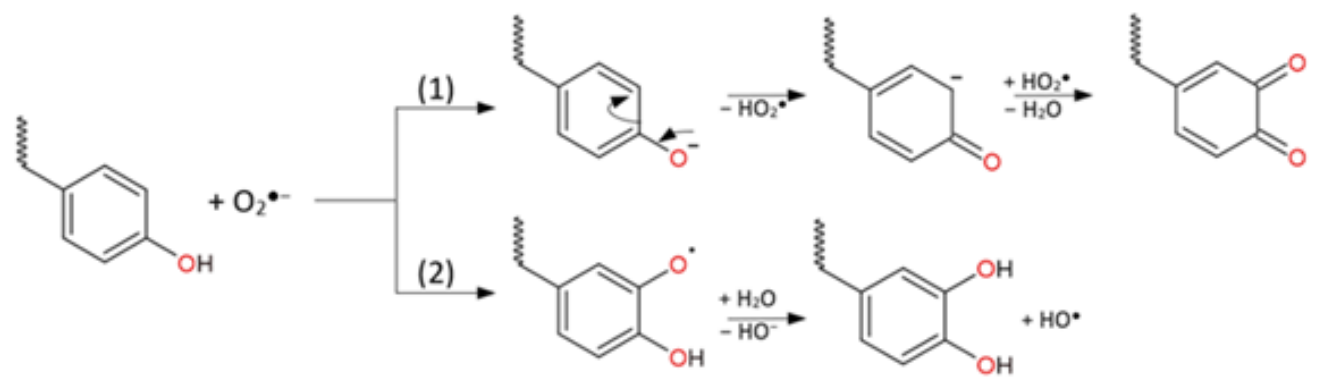

Figure 8

Proposed mechanism of oxidation of the phenolic rings of BPA 


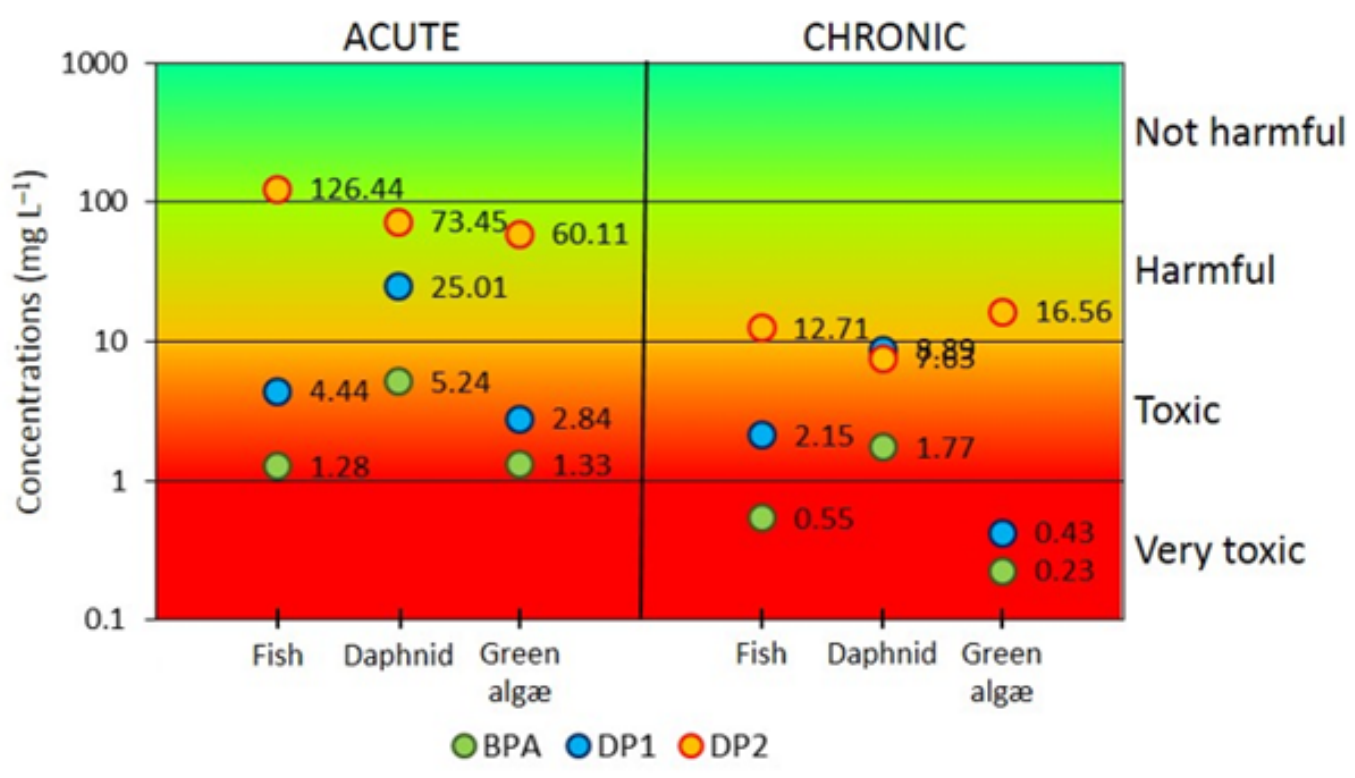

Figure 9

Estimated BPA, DP1, and DP2 acute* and chronic** ecotoxicities (ECOSAR 2.0 software) ) * Fish and Daphnid (LC50), Green algæ (EC50); LC50 = Lethal Concentration to 50\% of the population; EC50 = Effect Concentration to 50\% of the population. ** Fish, Daphnid, and Green algæ (ChV); ChV = Chronic Value .

\section{Supplementary Files}

This is a list of supplementary files associated with this preprint. Click to download.

- supplementarymaterialESRP.docx 